\title{
Fatigue in perinatal stroke is associated with the functional connectivity of the sensorimotor network.
}

Wrightson, J.G 1,2, Carlson, H.L 1,3,4 Condliffe, E.G 1,2,3 and Kirton, A 1,2,3,4.

1. Hotchkiss Brain Institute, University of Calgary, Calgary, AB, Canada

2. Department of Clinical Neurosciences, Cumming School of Medicine, University of Calgary, Calgary, AB, Canada

3. Alberta Children's Hospital Research Institute, Calgary, AB Canada

4. Department of Pediatrics, Cumming School of Medicine, University of Calgary, Calgary, AB, Canada

Keywords: Cerebral palsy, Resting state fMRI, Predictive coding, Active inference

Declaration of Interest statement:

The authors report no conflict of interest

This is a preprint. All authors have agreed to this preprint being made available. 
medRxiv preprint doi: https://doi.org/10.1101/2020.04.14.20065326; this version posted April 17, 2020. The copyright holder for this preprint (which was not certified by peer review) is the author/funder, who has granted medRxiv a license to display the preprint in perpetuity. It is made available under a CC-BY-NC-ND 4.0 International license .

\section{Abstract}

Fatigue is prevalent in youth with perinatal stroke, but the causes are unclear. Predictive coding models of adult post-stroke fatigue suggest that fatigue arises from dysfunction in a sensorimotor prediction processing network. To date, the association between fatigue and sensorimotor network connectivity in youth with perinatal stroke has not been examined. The aim of the present study was to examine the association between fatigue and the function of the cortical sensorimotor prediction network in children with hemiparetic perinatal stroke. Resting-state functional magnetic resonance imaging was used to measure the functional connectivity between sensorimotor areas in youth with perinatal stroke. Self-reported fatigue was associated with stronger functional connectivity between the non-lesioned somatosensory cortex and the lesioned supplementary motor area. In contrast, fatigue was also associated with weaker functional connectivity between the lesioned and non-lesioned thalamus. In support of sensorimotor dysfunction models of post-stroke fatigue, these results indicate that fatigue in youth with hemiparetic perinatal stroke is associated with the functional connectivity of the sensorimotor prediction network. These results present potential cortical and behavioural targets for the treatment of fatigue in individuals with perinatal stroke.

\section{Introduction}

Perinatal stroke is the leading cause of hemiparetic cerebral palsy and results in lifelong physical disability (Sreenan et al., 2000; Wu et al., 2004). Fatigue is common in individuals with hemiparetic cerebral palsy, including those with perinatal stroke (Maher et al., 2015; Russchen et al., 2014; Wrightson et al., 2019). Although fatigue significantly reduces health-related quality of life in individuals with cerebral palsy (Brunton, 2018; Brunton and Bartlett, 2013; Hilberink et al., 2007), the mechanisms which give rise to fatigue are not well understood and, consequently, there are few evidence-based treatments.

The predictive coding models of fatigue suggest that insult to the central nervous system causes an incongruity between the efferent sensory predictions encoded by the brain's generative model of the body, and the afferent sensory prediction errors that arise from an action (Brown et al., 2013; Kuppuswamy, 2017). Afferent prediction errors signal a required adjustment of either the generative model of the body, or the descending predictions issued by the brain which result in action (Adams et al., 2013; Pezzulo et al., 2015). These adjustments ensure that the ascending 
medRxiv preprint doi: https://doi.org/10.1101/2020.04.14.20065326; this version posted April 17, 2020. The copyright holder for this preprint (which was not certified by peer review) is the author/funder, who has granted medRxiv a license to display the preprint in perpetuity. It is made available under a CC-BY-NC-ND 4.0 International license .

sensory signals more closely match the predictions held by the generative model. Typically, prediction errors are suppressed (or attenuated) by the updated descending efferent predictions as the brain updates its predictive model or issues altered predictions/motor commands (Kuppuswamy et al., 2015b, 2015a). Damage to the central nervous system is proposed to impair this sensory attenuation, resulting in a continued discrepancy between sensory predictions and prediction errors, which in turn signals ongoing and unmanageable failure of the brain to predict the body state (Kuppuswamy, 2017; Kuppuswamy et al., 2015b). This signal is perceived as a feeling of fatigue (Kuppuswamy, 2017; Kuppuswamy et al., 2015b). Primary and secondary motor and sensory cortices are proposed to sit at the centre of a sensorimotor predictive coding network which both generates efferent sensory and motor predictions. They relay and respond to afferent sensorimotor prediction errors. (Figure 1, for detailed reviews see (Adams et al., 2013; Shipp et al., 2013). Dysfunction in this sensorimotor prediction network is assumed to result in the ongoing discrepancies between sensory predictions and errors and gives rise to fatigue (Kuppuswamy, 2017). However, to date, the association between fatigue and the activity of the sensorimotor prediction network has not been examined.

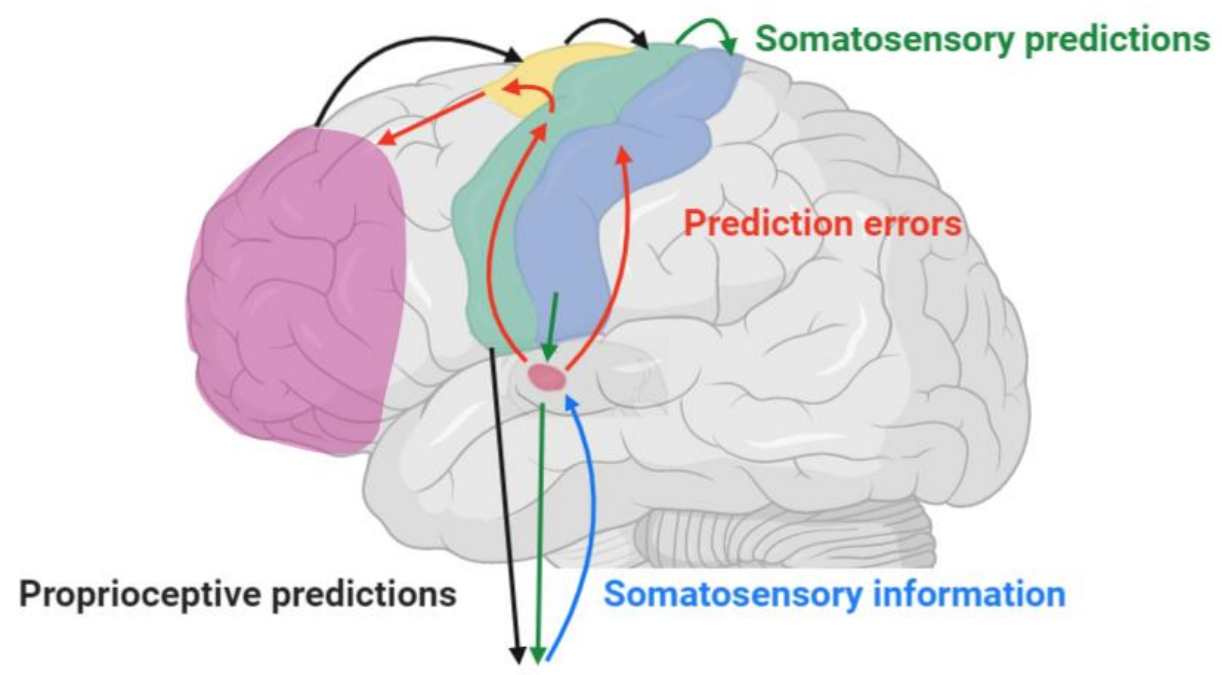

Figure 1. Simplified cartoon of the pathways involved in sensorimotor predictive coding. The primary motor cortex sits at the centre of a sensorimotor predictive coding network. To perform motor actions, the brain issues proprioceptive predictions (black arrows) via the motor cortex, to be fulfilled by downstream spinal motor reflexes and alpha motoneurons, resulting in action, e.g. striated muscle contraction. Simultaneously, somatosensory predictions (green arrows) are sent from motor cortex to the primary somatosensory cortex and onward via the thalamus to spinal motor circuits. Afferent sensory information resulting from an action (blue arrow) is projected from the periphery to the thalamus where it is compared to the descending somatosensory predictions. The results of these comparisons become prediction errors (red arrows) when there are discrepancies between the contained sensory information and the descending sensory predictions. Prediction errors are relayed to frontal association areas, via secondary motor and 
medRxiv preprint doi: https://doi.org/10.1101/2020.04.14.20065326; this version posted April 17, 2020. The copyright holder for this preprint (which was not certified by peer review) is the author/funder, who has granted medRxiv a license to display the preprint in perpetuity. It is made available under a CC-BY-NC-ND 4.0 International license .

sensory areas. Frontal areas can increase or decrease the precision (or gain) of prediction errors so that goal-relevant updated predictions can be subsequently issued to primary sensorimotor cortices. Typically, afferent sensory prediction errors are attenuated by the descending updated efferent predictions at the thalamus, or distally at spinal circuits (not shown). Pathological chronic feelings of fatigue arise when there are continued and unresolvable prediction errors that signal an ongoing and unmanageable failure of the brain to predict the body state. For detailed reviews see (Adams et al., 2013; Kuppuswamy, 2017; Shipp et al., 2013).

The symptom of fatigue in individuals with hemiparetic perinatal stroke can be interpreted using this predictive coding framework. Following perinatal brain injury, descending ipsilateral projections from the non-lesioned hemisphere to the more affected limbs are often preserved (Eyre, 2007). Conversely, afferent sensory projections are still received in the lesioned hemisphere (Gupta et al., 2017; Staudt et al., 2006; Thickbroom et al., 2001). In individuals with perinatal stroke, ipsilateral projections are linked with poorer motor performance (Kuo et al., 2018; Zewdie et al., 2017) but lower levels of fatigue (Wrightson et al., 2019). These findings suggest that sensorimotor connections in the non-lesioned hemisphere, which controls both hands but receives only contralateral afferent sensory projections, contributes to perception of fatigue in these individuals. Unlike in adult stroke, where pre-stroke conditions and acute pro-inflammatory responses following stroke are frequently assumed to contribute to the subsequent development of chronic late fatigue (Doncker et al., 2017; Wu et al., 2015), fatigue in perinatal stroke is likely to be a consequence of the abnormal development of the sensorimotor system (Wrightson et al., 2019). Using resting-state functional magnetic resonance imaging (rsfMRI), it has been reported that youth with perinatal stroke have abnormal functional connectivity of the sensorimotor system (Saunders et al., 2019; Woodward et al., 2019). At present, the relationship between fatigue and the functional connectivity of the sensorimotor prediction network has not been studied.

The aim of the present study was to examine the associations between fatigue and the functional connectivity of the sensorimotor prediction network in individuals with perinatal stroke and compare this to the functional connectivity of typically developed youth. We hypothesized that the functional connectivity of the sensorimotor processing network would be weaker in participants experiencing more fatigue (Kleckner et al., 2017; Siman-Tov et al., 2019; Stephan et al., 2016). 


\section{Method and Measures}

\subsection{Participants}

Participants were recruited via the Alberta Perinatal Stroke Project (Cole et al., 2017) and the Healthy Infants and Children Clinical Research Program (www.hiccupkids.ca) research cohorts, at the Alberta Children's Hospital. Inclusion criteria for participants with perinatal stroke were: age 6-19 years; term birth; magnetic resonance imaging (MRI)-confirmed unilateral perinatal arterial ischemic stroke (AIS) or periventricular venous infarction (PVI), symptomatic hemiparetic cerebral palsy including Pediatric Stroke Outcome Measure $>0.5$; Manual Ability Classification Scale levels I-IV. Inclusion criteria for typically developed controls (TDC) were: right-handed, ages 6-19 years, no neurological conditions, medications, or MRI contraindications. All participants and parents provided written informed assent/consent. Experiments were carried out with the approval of the Research Ethics Board at the University of Calgary and in accordance with the declaration of Helsinki (World Medical Association, 2013).

\subsection{Fatigue}

Self-reported fatigue was assessed in participants with perinatal stroke using the fatigue subscale of the Pediatric Quality of Life Inventory 3.0 cerebral palsy module (PEDSQL-CP), a validated measure of quality of life in children with CP (Varni et al., 2006). The fatigue subscale consists of four statements: "I feel tired”, “I feel physically weak (not strong)", “I rest a lot" and "I don't have enough energy to do things that I like to do". Individuals were asked to give a rating of 0-4 for each statement if they never (0), almost never (1), sometimes (2), often (3), or almost always (4) experienced a problem with the four areas of fatigue highlighted in the statements. Parents assisted children under 8 years with the rating using the PEDSQL 3.0 CP module parent report for young children. The PEDSQL scores for fatigue were reverse scored and linearly transformed to a 0 to 100 scale (Varni et al., 2006). The average score across all categories in each subscale was calculated. Lower scores in each subscale represent higher levels of fatigue. Participants were classified as experiencing fatigue if they scored $\leq 68.75$, indicating a problem with at least two or more of the categories of fatigue, or if they scored 4 ("almost always" a problem) for one of the categories 5 . 
medRxiv preprint doi: https://doi.org/10.1101/2020.04.14.20065326; this version posted April 17, 2020. The copyright holder for this preprint (which was not certified by peer review) is the author/funder, who has granted medRxiv a license to display the preprint in perpetuity. It is made available under a CC-BY-NC-ND 4.0 International license .

\subsection{MRI collection}

MRI sequences were acquired using a standardized perinatal stroke neuroplasticity protocol at the Alberta Children's Hospital Diagnostic Imaging Suite using a 3.0 Tesla GE MR750w MRI scanner (GE Healthcare, Waukesha, WI) with an MR Instruments 32-channel head coil. Highresolution T1-weighted anatomical images were acquired in the axial plane [166 contiguous slices; voxel size $=1.0 \mathrm{~mm}$ isotropic; repetition time $(\mathrm{TR})=8.5 \mathrm{~ms}$; echo time $(\mathrm{TE})=3.2 \mathrm{~ms}$. Resting-state fMRI acquisition used 150 T2-weighted whole-brain echo-planar volumes (EPI; 36 interleaved contiguous slices; voxel size $=3.6 \mathrm{~mm}$ isotropic; TR/TE $=2000 / 30 \mathrm{~ms}$ ). Participants were told to fixate on a centrally presented cross. Since the location of stroke could occur in either hemisphere, images were reoriented such that the stroke was located in the right hemisphere for all patients so that lesioned hemispheres of patients corresponded to non-dominant hemispheres in controls. Therefore, hemispheres in patients are referred to as lesioned vs non-lesioned.

\subsection{Functional connectivity analyses}

Resting-state functional connectivity analyses were performed using the SPM12 (Statistical Parametric Mapping, Wellcome Trust, UCL, UK) Functional Connectivity Toolbox (CONN) (Whitfield-Gabrieli and Nieto-Castanon, 2012) in Matlab version r2018a (Mathworks, Natick, MA, USA). Slice timing correction, realignment, and co-registration were performed, and head motion parameters were estimated. Co-registered images were segmented using standard SPM tissue probability maps. Images were normalized into Montreal Neurological Institute (MNI) space via direct non-linear transformations using the standard 152-average template. Direct normalization results in structural and functional volumes being separately normalized to MNI space. Images were then smoothed with a $6 \mathrm{~mm} 3$ full-width at half-maximum Gaussian kernel. Head motion exceeding $0.9 \mathrm{~mm}$ of translational head movement and global intensity outliers ( $z$-score $>5)$ were identified using the Artifact Repair Toolbox (Mazaika et al., 2007). Time courses of blood oxygenation level-dependent (BOLD) responses were extracted for the GM, CSF and WM. The CSF and WM time courses were regressed out of the general linear regression model (GLM). Outlier volumes and head motion were de-weighted in the GLM.

ROI-to-ROI functional connectivity strengths for stroke participants were first calculated using eight predetermined ROl's within the sensorimotor prediction network. ROl's were identified from previous neuroimaging data (Siman-Tov et al., 2019) and theoretical accounts of sensorimotor predictive coding (Adams et al., 2013; Feldman Barrett and Simmons, 2015). These included the 
medRxiv preprint doi: https://doi.org/10.1101/2020.04.14.20065326; this version posted April 17, 2020. The copyright holder for this preprint (which was not certified by peer review) is the author/funder, who has granted medRxiv a license to display the preprint in perpetuity. It is made available under a CC-BY-NC-ND 4.0 International license .

bilateral primary motor (M1) and somatosensory (S1) cortices, the supplementary motor area (SMA), and the thalamus. BOLD signal time-series were calculated using the average of all voxels within the ROI. Fisher-transformed correlation coefficients were interpreted as quantifications of functional connectivity (FC) strength between areas. FC between each of the ROls and clusters were identified in CONN. We extracted FC values for two subsequent analyses: First, the FC between each ROI (M1, S1, SMA, thalamus) in the lesioned and non-lesioned hemispheres were extracted from the first level ROI-to-ROI analysis for each participant. Certain clusters were identified as predictive of fatigue using an elastic-net regression model (described below), and these FC values were subsequently quantified in TDC to compare functional connectivity between participant groups.

\section{5 Statistical analysis}

Statistical analyses were performed with the $\mathrm{R}$ statistical software package ( $\mathrm{R}$ Development Core Team, 2011). Initially, stroke participants' Fisher-transformed FC (N = 30 clusters), demeaned age and stroke type (AIS or PVI infarction) were entered into an elastic net regularized regression model, with fatigue score as the outcome variable. Five-fold cross-validated binomial elastic net regression was performed using the 'glmnet' package (Friedman et al., 2010). A subsequent linear regression model containing predictors identified in the model was used to determine model-goodness of fit. As a robustness check, this analysis was then repeated using fatigue group as the dependent variable. FC identified in the elastic net model were compared between groups (Fatigued, Not fatigued, TDC) using analysis of variance (ANOVA). Shapiro-Wilk's test of normality was used to assess the distribution of the residual, and Levene's test was used to determine the homogeneity of variance. Cohen's $d$ and its associated 95\% confidence interval were used as an estimate of the effect sizes for differences in FC between groups. For stroke patients, the association between the PEDSQL-CP fatigue score and FC identified as significant predictors of fatigue group were calculated using Spearman correlations. The threshold to reject the null hypothesis was set at $p<0.05$, the false-discovery rate was adjusted to control for multiple comparisons (Benjamini et al., 2006). 
medRxiv preprint doi: https://doi.org/10.1101/2020.04.14.20065326; this version posted April 17, 2020. The copyright holder for this preprint (which was not certified by peer review) is the author/funder, who has granted medRxiv a license to display the preprint in perpetuity.

\section{Results}

Seventy-five participants were identified through the Alberta Perinatal Stroke Project database. Of these, eleven were ineligible due to incomplete data at the time of analysis, and four were removed due to excessive head motion in the scanner. The data for 60 stroke participants and 32 TDC were included in the analysis. Participant demographics and outcomes are summarized in Table 1. The median age for the full sample was 11 years, range $7-19$ years, and $35 \%$ were female. Fifty-three percent (32/60) of the participants with perinatal stroke reported experiencing problems with fatigue (PESQL-CP fatigue score $\leq 68.75$ ) and were assigned to the "Fatigued" group (Wrightson et al., 2019) and the remaining 28 participants were assigned to the "Not Fatigued" group. There was no difference in age between the stroke groups or between stroke and TDC participants. Fatigue scores were not associated with stroke type or sex $(p>0.05)$.

Table 1. Demographics characteristics and fatigue scores

\begin{tabular}{|c|c|c|c|c|}
\hline & $\begin{array}{l}\text { Stroke } \\
(\mathrm{N}=60)\end{array}$ & $\begin{array}{l}\text { Fatigued } \\
(\mathrm{N}=32)\end{array}$ & $\begin{array}{l}\text { Not fatigued } \\
\quad(N=28)\end{array}$ & $\begin{array}{c}\text { TDC } \\
(\mathrm{N}=34)\end{array}$ \\
\hline $\begin{array}{c}\text { Sex } \\
\text { (Female: Male) }\end{array}$ & 21:39 & $14: 18$ & $7: 21$ & $15: 19$ \\
\hline $\begin{array}{c}\text { Age } \\
\text { (years, mean }+S D \text { ) }\end{array}$ & $11.5 \pm 2.9$ & $11.9+2.8$ & $11.2 \pm 3.1$ & $13.2 \pm 3.6$ \\
\hline $\begin{array}{l}\text { Stroke side } \\
\text { (Left: Right) }\end{array}$ & $37: 23$ & $19: 13$ & $18: 10$ & NA \\
\hline $\begin{array}{c}\text { Stroke type } \\
\text { (Arterial: Periventricular } \\
\text { Venous Infarction) }\end{array}$ & 29:31 & $16: 16$ & $13: 15$ & NA \\
\hline $\begin{array}{c}\text { Fatigue } \\
\text { (PEDSQL, median [IQR]) }\end{array}$ & $\begin{array}{l}68.8[56.2- \\
\quad 82.8]\end{array}$ & $\begin{array}{c}52.1 \\
{[48.4-62.5]}\end{array}$ & $\begin{array}{c}87.7 \\
{[75-100]}\end{array}$ & NA \\
\hline
\end{tabular}

NA; not recorded in control participants

\subsection{Associations between functional connectivity and fatigue score}

Variable selection was performed using 5-fold cross-validated binomial elastic-net regression. Fisher-transformed correlation coefficients for ROI-to-ROI connections, age and stroke type (AIS or PVI) were entered into the model. The model identified two ROI-to-ROI connections as significant predictors of fatigue status. FC between the non-lesioned S1 and lesioned SMA $(\beta=$ 
medRxiv preprint doi: https://doi.org/10.1101/2020.04.14.20065326; this version posted April 17, 2020. The copyright holder for this preprint (which was not certified by peer review) is the author/funder, who has granted medRxiv a license to display the preprint in perpetuity.

It is made available under a CC-BY-NC-ND 4.0 International license .

-21.7, $\mathrm{SE}=9.9, p=0.032)$ and the lesioned and non-lesioned thalamus $(\beta=15.5, \mathrm{SE}=7.5, p=$ $0.032)$ were significant predictors of fatigue score $\left(R_{2}=0.15, F(2,57)=4.9, p=0.017\right.$, Figure 2$)$.

A

- Fatigued $\Delta$ Not Fatigued

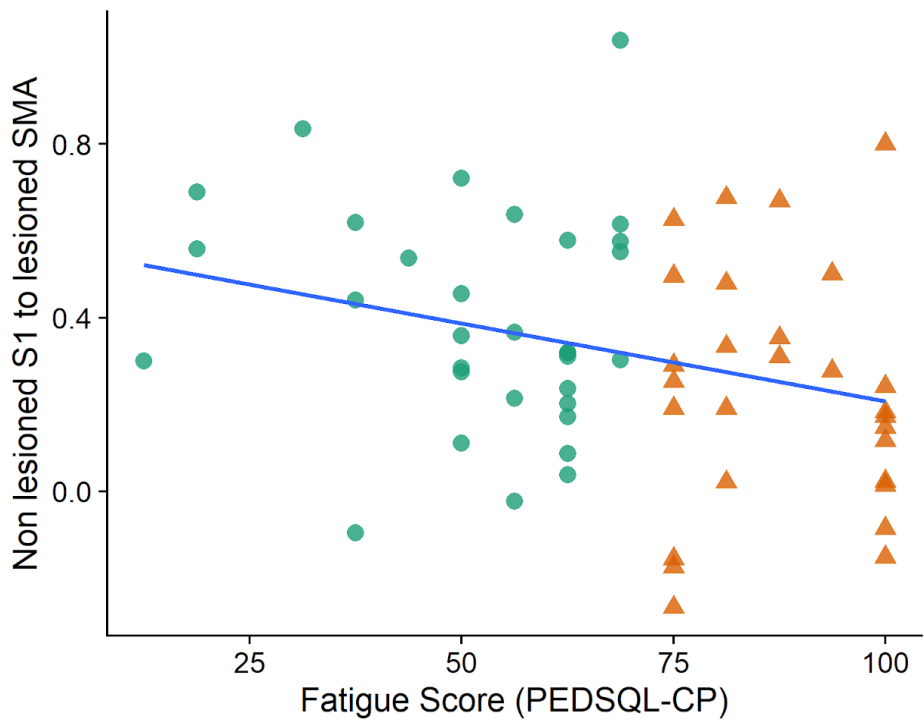

B

- Fatigued $\Delta$ Not Fatigued

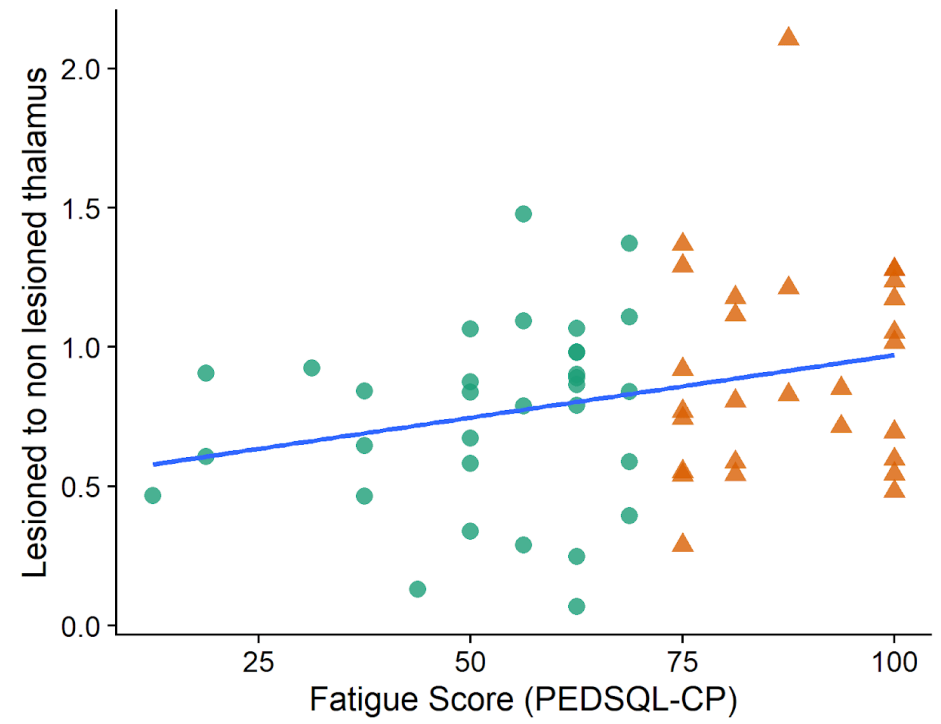

Figure 2. Associations (linear regression) between fatigue score and FC between non-lesioned S1 and lesioned SMA (A) and lesioned to non-lesioned thalamus (B). A lower fatigue score represents higher levels of fatigue, positive associations thus indicate stronger connectivity is associated with lower fatigue, negative associations indicate weaker connectivity is associated with lower fatigue.

\subsection{Group comparisons}

Means and standard deviations for the Fisher-transformed correlations between ROI-ROI clusters are shown in Table 2. ANOVA $(F(2,91)=3.3, p=0.032)$ revealed a difference between groups for the FC between the non-lesioned (or left in TDC) S1 and lesioned SMA. Participants in the Fatigued group had stronger connectivity between the non-lesionedVleft S1 and lesioned \right } SMA compared to the Not Fatigued group $(p=0.020, d=0.62[95 \% \mathrm{Cl}=0.08,1.14]$, Figure $3 \mathrm{~A})$. There was no difference between the Fatigued group and TDC $(p=0.351, d=0.13[95 \% \mathrm{Cl}=$ $0.35,0.62])$. FC between the non-lesioned/left S1 and lesioned/right SMA was weaker in the Not Fatigued group compared to $\operatorname{TDC}(p=0.032, d=0.52[95 \% \mathrm{Cl}=-0.01,1.03])$. 
medRxiv preprint doi: https://doi.org/10.1101/2020.04.14.20065326; this version posted April 17, 2020. The copyright holder for this preprint (which was not certified by peer review) is the author/funder, who has granted medRxiv a license to display the preprint in perpetuity.

It is made available under a CC-BY-NC-ND 4.0 International license .

Table 2. Means \pm SD for Fisher-transformed correlations for the seed-to-voxel analysis

\begin{tabular}{lccc}
\hline & $\begin{array}{c}\text { Fatigued } \\
(\mathrm{N}=28)\end{array}$ & $\begin{array}{c}\text { Not Fatigued } \\
(\mathrm{N}=27)\end{array}$ & $\begin{array}{c}\text { TDC } \\
(\mathrm{N}=32)\end{array}$ \\
\hline Non-lesioned S1- lesioned SMA & $0.40 \pm 0.26$ & $0.23 \pm 0.29$ & $0.36 \pm 0.23$ \\
Lesioned thalamus - non-lesioned thalamus & $0.75 \pm 0.34$ & $0.92 \pm 0.38$ & $1.16 \pm 0.25$ \\
\hline
\end{tabular}

S1; primary somatosensory cortex, SMA; supplementary motor area

There was also a difference between groups for the FC between the lesioned and non-lesioned thalamus $(F(2,91)=13.3, p=0.003)$. Participants in the Fatigued group had weaker FC compared to the Not Fatigued group $(p=0.003, d=0.48[-0.05,0.99])$ and TDC $(p=0.003, d=1.41[0.80$, 2.00]). FC was also weaker in the Not Fatigued group compared to TDC ( $p=0.008, d=0.78$ [0.23, 1.31], Figure 3B).
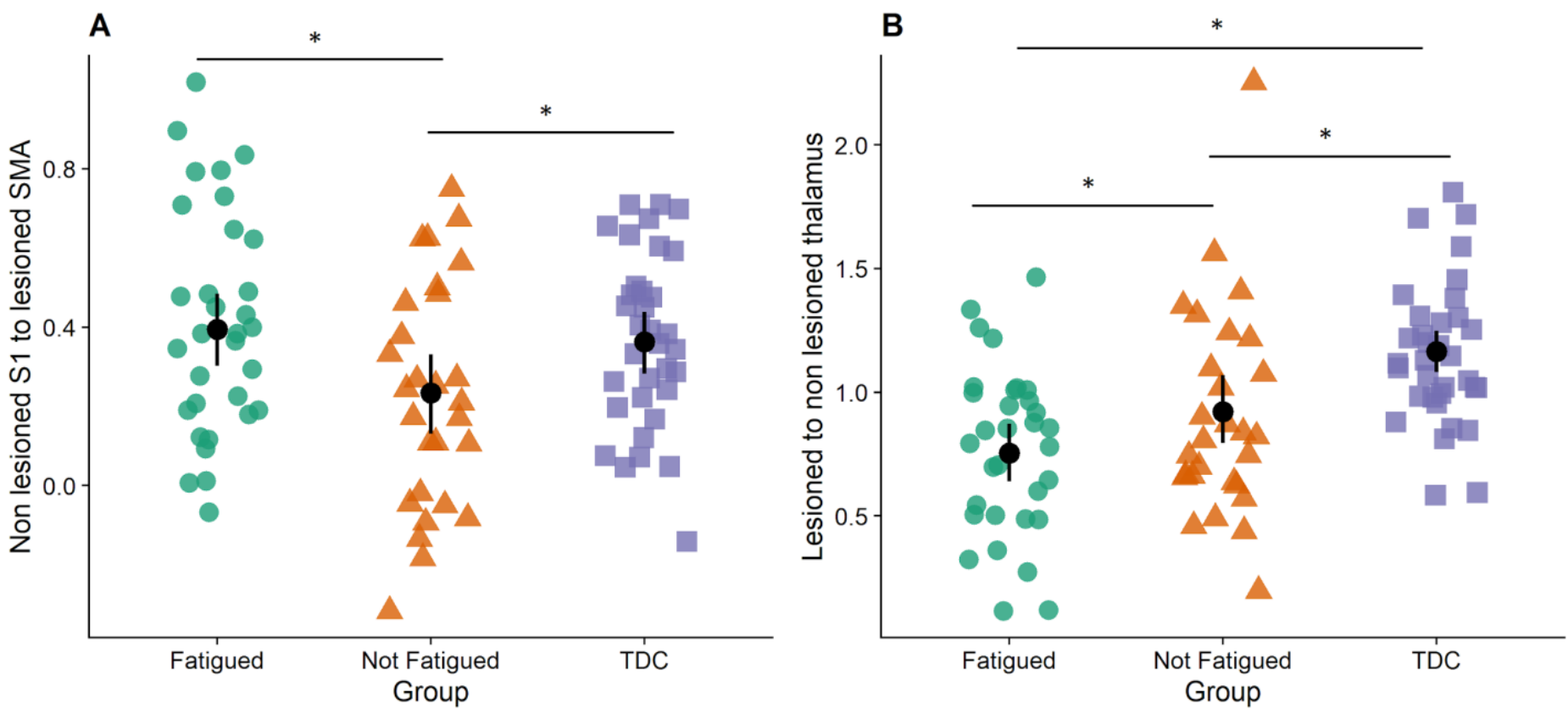

Figure 3. Fisher-transformed correlation coefficients for the connectivity between the nonlesioned primary somatosensory cortex and lesioned supplementary motor area $(A)$ and between the non-lesioned and lesioned thalamus (B). The black circle and error bars represent the mean $\pm 95 \%$ confidence interval. *; a difference $(p<0.05)$ between groups. TDC; Typically developed controls. 
medRxiv preprint doi: https://doi.org/10.1101/2020.04.14.20065326; this version posted April 17, 2020. The copyright holder for this preprint (which was not certified by peer review) is the author/funder, who has granted medRxiv a license to display the preprint in perpetuity. It is made available under a CC-BY-NC-ND 4.0 International license .

\section{Discussion}

The aim of the present study was to examine the associations between fatigue and resting-state functional connectivity of the sensorimotor network in individuals with perinatal stroke. Compared to participants who were not fatigued, participants who reported problems with fatigue had stronger connectivity between the non-lesioned S1 and the lesioned SMA. In contrast, fatigued participants also had weaker connectivity between the lesioned and non-lesioned thalamus compared to those with no fatigue. This study is the first to explicitly test the relationship between the connectivity of the sensorimotor network and perceived fatigue. These results support the suggestion that in individuals with perinatal stroke-induced cerebral palsy, fatigue is related to the functional connectivity of the sensorimotor prediction network.

Predictive coding theoretical frameworks suggest that the brain contains a generative model of the body-state (Friston, 2008). Within these frameworks, fatigue arises from an ongoing and unresolvable discrepancy between the brain's prediction of the body-state, and the afferent sensory information signalling the actual-body state (the prediction) (Kuppuswamy, 2017; Manjaly et al., 2019; Stephan et al., 2016). These prediction errors signal a failure for the brain to predict the body state, i.e. an inability to maintain homeostasis. This ongoing discrepancy between predicted and actual body state is consciously perceived as the feeling of fatigue, which acts as a signal for allostatic behavioural adjustment: rest 9,17,38. What is important to note about these models is that fatigue is not necessarily a direct result of alterations to physical capacity per se, but can be caused by impaired sensorimotor processing, even when motor-function can be near normal. Although several prominent theoretical accounts have been proposed (Kuppuswamy et al., 2015b; Manjaly et al., 2019; Stephan et al., 2016), there have been few experimental examinations of these models (but for example see (van der Schaaf et al., 2018)). Here, we provide evidence from resting-state fMRI indicating that fatigue in perinatal stroke is associated with altered connectivity within a sensorimotor prediction network. In the present study, the strength of connections between areas within a previously identified predictive coding sensorimotor network (Adams et al., 2013) was different in individuals with perinatal stroke who reported problems with fatigue, compared to those with little or no fatigue. The differences seen here were not dependent on stroke type, indicating they cannot only be a consequence of stroke mechanism. Instead, these data support the suggestion that fatigue in perinatal stroke is related to dysfunction in a sensorimotor predictive coding network (Kuppuswamy et al., 2015b; Turner et al., 2019; Wrightson et al., 2019). 
medRxiv preprint doi: https://doi.org/10.1101/2020.04.14.20065326; this version posted April 17, 2020. The copyright holder for this preprint (which was not certified by peer review) is the author/funder, who has granted medRxiv a license to display the preprint in perpetuity. It is made available under a CC-BY-NC-ND 4.0 International license .

We found a difference in functional connectivity in cortical sensory and motor areas, suggestive of a "higher-level" compensatory mechanism. Individuals who reported problems with fatigue had stronger connectivity between the non-lesioned primary somatosensory cortex and lesioned supplementary motor area. The primary motor and somatosensory cortices are suggested to sit at the centre of a hierarchical cortical network which models (i.e. predicts) the proprioceptive consequences of an action. (Adams et al., 2013; Brown et al., 2013; Shipp et al., 2013). Prediction errors are received and relayed between primary and secondary motor and sensory cortices (Adams et al., 2013). The SMA has long been suggested to be involved in motor prediction/planning (Tanji and Shima, 1994) and more recent evidence also links anterior SMA with somatosensory predictions (Jung et al., 2018) suggesting the connectivity seen here is related to sensorimotor prediction. That this functional connectivity was between non-lesioned S1 and the lesioned SMA is congruent with previous observations in children with hemiparetic CP. In many individuals with hemiparetic $\mathrm{CP}$, the contralesional primary motor cortex is a major source of motor output to both affected and less affected limbs, however the ipsilesional somatosensory cortex still receives, and relays sensory signals (Staudt, 2010). Here, individuals who experienced problems with fatigue had stronger connectivity between non-lesioned and lesioned sensorimotor cortices. This finding raises the intriguing possibility that participants who experience less fatigue do so because of the greater dissociation between the lesioned motor area and non-lesioned sensory areas. Within a predictive coding framework, this dissociation might limit the gain or transmission of ascending prediction errors, resulting in reduced signalling of sensorimotor dysfunction. However, it is not possible to infer causality from this observational data: it is possible that fatigue arises from dysfunction in downstream areas, and the persistent feeling of fatigue contributes to the functional connectivity in these areas. We consider this unlikely however, because functional connectivity between contralateral sensory and motor cortices appears to occur in typical development.

The finding that FC between lesioned and non-lesioned thalami in the fatigued group was significantly lower than both the non-fatigued and TDC groups is consistent with a sensory dysfunction hypothesis. Sensory attenuation of afferent prediction errors is suggested to occur, at least in part, at the thalamus 12. If afferent sensory feedback is somehow compromised due to perinatal stroke-induced damage this could manifest as reduced functional connectivity within thalamic circuits. Interestingly, the weaker functional connectivity of the thalamus in the fatigued group was still quite strong (mean $r=0.75$ ) but not as strong as for the other two groups (both 
medRxiv preprint doi: https://doi.org/10.1101/2020.04.14.20065326; this version posted April 17, 2020. The copyright holder for this preprint (which was not certified by peer review) is the author/funder, who has granted medRxiv a license to display the preprint in perpetuity. It is made available under a CC-BY-NC-ND 4.0 International license .

rs>0.9), suggesting that reduced thalamic FC was not due to direct damage to the thalami by stroke lesions as the thalamus is mostly spared by in middle cerebral artery (MCA) strokes. The finding that FC was positively correlated with fatigue rating scales (i.e., reduced interhemispheric thalamic FC is related to more fatigue) is an interesting confirmation of clinical relevance. Indeed, previous findings in this patient group have shown bilateral thalamic diaschisis 42 and differences in sensory tract white matter microstructure 43 compared to TDC that are both highly related to motor and sensory function, respectively. Subcortical structures such as the thalamus and basal ganglia should be carefully considered in further studies of sensorimotor functional connectivity in perinatal stroke-induced cerebral palsy especially given their integral roles in the direct and indirect motor pathways 44.

These results suggest non-lesioned sensorimotor areas as possible targets for interventions and may provide possible biomarkers with which to examine the mechanisms by which treatment influences fatigue. Of particular interest is the effect on the connectivity of this network of emerging neuromodulation therapies such as non-invasive brain stimulation 43,44 and novel sensorimotor training paradigms using robotic exoskeletons 45. Unfortunately, causal effects cannot be established in an observational study such as this. Instead, the examination of changes to the connectivity of the network identified here before and after treatment, may give greater insight into the relevance of these effects. Additionally, replication of these effects in adult-stroke where plastic development of the central nervous system is unlikely to have occurred following insult, at least to the same degree as in perinatal stroke, may help develop a broader picture of how these changes in network connectivity respond to insult, and their association with fatigue.

This study has some limitations which should be acknowledged. We have used the predictive coding theories of the brain and affect as a framework through which we interpreted our results. While our data provide support for these models, we did not measure the activity of this network during an action (e.g. (Turner et al., 2019)), nor did we have a measure of predictive coding during performance (e.g. (van der Schaaf et al., 2018)). These are the necessary next steps in the examination of fatigue in youth with perinatal stroke. Although we applied post-hoc corrections for head movement, $\mathrm{fMRI}$ remains a challenging technique in a pediatric population, and we were required to remove several participants from our sample. The replication of these effects in adults with perinatal stroke may overcome this limitation and provide a method by which to replicate and extend these results. Our sample was composed of participants who were capable of completing 
medRxiv preprint doi: https://doi.org/10.1101/2020.04.14.20065326; this version posted April 17, 2020. The copyright holder for this preprint (which was not certified by peer review) is the author/funder, who has granted medRxiv a license to display the preprint in perpetuity.

It is made available under a CC-BY-NC-ND 4.0 International license .

an MRI which is necessarily the less-disabled and higher functioning portion of the perinatal stroke population.

\section{Conclusion}

We found that fatigue in individuals with perinatal stroke was associated with altered functional connectivity of a network implicated in sensorimotor predictive coding. These findings provide interesting avenues for both future research and therapeutic interventions. The effects of emerging therapies, such as novel sensorimotor training paradigms and non-invasive brain stimulation, on both neural functional connectivity and fatigue are warranted. 
medRxiv preprint doi: https://doi.org/10.1101/2020.04.14.20065326; this version posted April 17, 2020. The copyright holder for this preprint

(which was not certified by peer review) is the author/funder, who has granted medRxiv a license to display the preprint in perpetuity.

It is made available under a CC-BY-NC-ND 4.0 International license .

\section{References}

Adams, R.A., Shipp, S., Friston, K.J., 2013. Predictions not commands: Active inference in the motor system. Brain Struct. Funct. 218, 611-643. https://doi.org/10.1007/s00429-0120475-5

Benjamini, Y., Krieger, A.M., Yekutieli, D., 2006. Adaptive linear step-up procedures that control the false discovery rate. Biometrika 93, 491-507. https://doi.org/10.1093/biomet/93.3.491

Brown, H., Adams, R.A., Parees, I., Edwards, M., Friston, K., 2013. Active inference, sensory attenuation and illusions. Cogn. Process. 14, 411-427. https://doi.org/10.1007/s10339013-0571-3

Brunton, L.K., 2018. Descriptive Report of the Impact of Fatigue and Current Management Strategies in Cerebral Palsy. Pediatr. Phys. Ther. 30, 135-141. https://doi.org/10.1097/PEP.0000000000000490

Brunton, L.K., Bartlett, D.J., 2013. The bodily experience of cerebral palsy: a journey to selfawareness. Disabil. Rehabil. 35, 1981-1990. https://doi.org/10.3109/09638288.2013.770080

Cole, L., Dewey, D., Letourneau, N., Kaplan, B.J., Chaput, K., Gallagher, C., Hodge, J., Floer, A., Kirton, A., 2017. Clinical characteristics, risk factors, and outcomes associated with neonatal hemorrhagic stroke: A population-based case-control study. JAMA Pediatr. https://doi.org/10.1001/jamapediatrics.2016.4151

Doncker, W.D., Dantzer, R., Ormstad, H., Kuppuswamy, A., 2017. Mechanisms of poststroke fatigue. J Neurol Neurosurg Psychiatry jnnp-2017-316007. https://doi.org/10.1136/jnnp2017-316007

Eyre, J.A., 2007. Corticospinal tract development and its plasticity after perinatal injury. Neurosci. Biobehav. Rev., Lesions in the Developing Nervous System: Theoretical Considerations, Early Detection and Perspectives for Treatment 31, 1136-1149. https://doi.org/10.1016/j.neubiorev.2007.05.011

Feldman Barrett, L., Simmons, W.K., 2015. Interoceptive predictions in the brain. Nat. Rev. Neurosci. 16, 419-429. https://doi.org/10.1038/nrn3950

Friedman, J., Hastie, T., Tibshirani, R., 2010. Regularization Paths for Generalized Linear Models via Coordinate Descent. J. Stat. Softw. 33, 1-22.

Friston, K., 2008. Hierarchical Models in the Brain. PLOS Comput. Biol. 4, e1000211. https://doi.org/10.1371/journal.pcbi.1000211

Gupta, D., Barachant, A., Gordon, A.M., Ferre, C., Kuo, H.-C., Carmel, J.B., Friel, K.M., 2017. Effect of sensory and motor connectivity on hand function in pediatric hemiplegia. Ann. Neurol. 82, 766-780. https://doi.org/10.1002/ana.25080

Hilberink, S.R., Roebroeck, M.E., Nieuwstraten, W., Jalink, L., Verheijden, J.M.A., Stam, H.J., 2007. Health issues in young adults with cerebral palsy: towards a life-span perspective. J. Rehabil. Med. 39, 605-611. https://doi.org/10.2340/16501977-0103

Jung, W.-M., Ryu, Y., Park, H.-J., Lee, H., Chae, Y., 2018. Brain activation during the expectations of sensory experience for cutaneous electrical stimulation. Neurolmage Clin. 19, 982-989. https://doi.org/10.1016/j.nicl.2018.06.022

Kleckner, I.R., Zhang, J., Touroutoglou, A., Chanes, L., Simmons, W.K., Quigley, K.S., Dickerson, B.C., Barrett, F., 2017. Evidence for a Large-Scale System Supporting Allostasis and Interoception in Humand. Nat Hum Behav 1-37. https://doi.org/10.1038/s41562-017-0069

Kuo, H.-C., Zewdie, E., Ciechanski, P., Damji, O., Kirton, A., 2018. Intervention-Induced Motor Cortex Plasticity in Hemiparetic Children With Perinatal Stroke. Neurorehabil. Neural Repair 1545968318801546. https://doi.org/10.1177/1545968318801546 
medRxiv preprint doi: https://doi.org/10.1101/2020.04.14.20065326; this version posted April 17, 2020. The copyright holder for this preprint

(which was not certified by peer review) is the author/funder, who has granted medRxiv a license to display the preprint in perpetuity.

It is made available under a CC-BY-NC-ND 4.0 International license .

Kuppuswamy, A., 2017. The fatigue conundrum. Brain 140, 2240-2245. https://doi.org/10.1093/brain/awx153

Kuppuswamy, A., Clark, E.V., Turner, I.F., Rothwell, J.C., Ward, N.S., 2015a. Post-stroke fatigue: a deficit in corticomotor excitability? Brain J. Neurol. 138, 136-148. https://doi.org/10.1093/brain/awu306

Kuppuswamy, A., Rothwell, J., Ward, N., 2015b. A model of poststroke fatigue based on sensorimotor deficits. Curr. Opin. Neurol. 28, 582-586. https://doi.org/10.1097/WCO.0000000000000260

Maher, C., Crettenden, A., Evans, K., Thiessen, M., Toohey, M., Watson, A., Dollman, J., 2015. Fatigue is a major issue for children and adolescents with physical disabilities. Dev. Med. Child Neurol. 57, 742-747. https://doi.org/10.1111/dmcn.12736

Manjaly, Z.-M., Harrison, N.A., Critchley, H.D., Do, C.T., Stefanics, G., Wenderoth, N., Lutterotti, A., Müller, A., Stephan, K.E., 2019. Pathophysiological and cognitive mechanisms of fatigue in multiple sclerosis. J Neurol Neurosurg Psychiatry jnnp-2018-320050. https://doi.org/10.1136/jnnp-2018-320050

Mazaika, P., Hoeft, F., Glover, G., Reiss, A., 2007. Artifact Repair for fMRI Data from High Motion Clinical Subjects. Hum. Brain Mapp. San Franc. CA USA.

Pezzulo, G., Rigoli, F., Friston, K., 2015. Active Inference, homeostatic regulation and adaptive behavioural control. Prog. Neurobiol. 134, 17-35. https://doi.org/10.1016/j.pneurobio.2015.09.001

R Development Core Team, R., 2011. R: A language and environment for statistical computing. $R$ foundation for statistical computing Vienna, Austria.

Russchen, H.A., Slaman, J., Stam, H.J., van Markus-Doornbosch, F., van den Berg-Emons, R.J., Roebroeck, M.E., 2014. Focus on fatigue amongst young adults with spastic cerebral palsy. J. NeuroEngineering Rehabil. 11, 161. https://doi.org/10.1186/17430003-11-161

Saunders, J., Carlson, H.L., Cortese, F., Goodyear, B.G., Kirton, A., 2019. Imaging functional motor connectivity in hemiparetic children with perinatal stroke. Hum. Brain Mapp. 40, 1632-1642. https://doi.org/10.1002/hbm.24474

Shipp, S., Adams, R.A., Friston, K.J., 2013. Reflections on agranular architecture: predictive coding in the motor cortex. Trends Neurosci. 36, 706-716. https://doi.org/10.1016/j.tins.2013.09.004

Siman-Tov, T., Granot, R.Y., Shany, O., Singer, N., Hendler, T., Gordon, C.R., 2019. Is there a prediction network? Meta-analytic evidence for a cortical-subcortical network likely subserving prediction. Neurosci. Biobehav. Rev. 105, 262-275. https://doi.org/10.1016/j.neubiorev.2019.08.012

Sreenan, C., Bhargava, R., Robertson, C.M.T., 2000. Cerebral infarction in the term newborn: Clinical presentation and long-term outcome. J. Pediatr. 137, 351-355. https://doi.org/10.1067/mpd.2000.107845

Staudt, M., 2010. Reorganization after pre- and perinatal brain lesions. J. Anat. 217, 469-474. https://doi.org/10.1111/j.1469-7580.2010.01262.x

Staudt, M., Braun, C., Gerloff, C., Erb, M., Grodd, W., Krägeloh-Mann, I., 2006. Developing somatosensory projections bypass periventricular brain lesions. Neurology 67, 522-525. https://doi.org/10.1212/01.wnl.0000227937.49151.fd

Stephan, K.E., Manjaly, Z.M., Mathys, C.D., Weber, L.A.E., Paliwal, S., Gard, T., Tittgemeyer, M., Fleming, S.M., Haker, H., Seth, A.K., Petzschner, F.H., 2016. Allostatic Self-efficacy: A Metacognitive Theory of Dyshomeostasis-Induced Fatigue and Depression. Front. Hum. Neurosci. 10, 550. https://doi.org/10.3389/fnhum.2016.00550

Tanji, J., Shima, K., 1994. Role for supplementary motor area cells in planning several movements ahead. Nature 371, 413-416. https://doi.org/10.1038/371413a0 
medRxiv preprint doi: https://doi.org/10.1101/2020.04.14.20065326; this version posted April 17, 2020. The copyright holder for this preprint

(which was not certified by peer review) is the author/funder, who has granted medRxiv a license to display the preprint in perpetuity. It is made available under a CC-BY-NC-ND 4.0 International license .

Thickbroom, G.W., Byrnes, M.L., Archer, S.A., Nagarajan, L., Mastaglia, F.L., 2001. Differences in sensory and motor cortical organization following brain injury early in life. Ann. Neurol. 49, 320-327.

Turner, I.F., Ward, N.S., Kuppuswamy, A., 2019. Fatigue, effort perception and central activation failure in chronic stroke survivors: a TMS and $\mathrm{FMRI}$ investigation. bioRxiv 821959. https://doi.org/10.1101/821959

van der Schaaf, M.E., Roelofs, K., de Lange, F.P., Geurts, D.E.M., van der Meer, J.W.M., Knoop, H., Toni, I., 2018. Fatigue Is Associated With Altered Monitoring and Preparation of Physical Effort in Patients With Chronic Fatigue Syndrome. Biol. Psychiatry Cogn. Neurosci. Neuroimaging 3, 392-404. https://doi.org/10.1016/j.bpsc.2018.01.015

Varni, J.W., Burwinkle, T.M., Berrin, S.J., Sherman, S.A., Artavia, K., Malcarne, V.L., Chambers, H.G., 2006. The PedsQL in pediatric cerebral palsy: reliability, validity, and sensitivity of the Generic Core Scales and Cerebral Palsy Module. Dev. Med. Child Neurol. 48, 442. https://doi.org/10.1017/S001216220600096X

Whitfield-Gabrieli, S., Nieto-Castanon, A., 2012. Conn: a functional connectivity toolbox for correlated and anticorrelated brain networks. Brain Connect. 2, 125-141. https://doi.org/10.1089/brain.2012.0073

Woodward, K.E., Carlson, H.L., Kuczynski, A., Saunders, J., Hodge, J., Kirton, A., 2019. Sensory-motor network functional connectivity in children with unilateral cerebral palsy secondary to perinatal stroke. Neurolmage Clin. 21, 101670. https://doi.org/10.1016/j.nicl.2019.101670

World Medical Association, 2013. World Medical Association Declaration of Helsinki: ethical principles for medical research involving human subjects. JAMA 310, 2191-2194. https://doi.org/10.1001/jama.2013.281053

Wrightson, J.G., Zewdie, E., Kuo, H.-C., Millet, G.Y., Kirton, A., 2019. Fatigue in children with perinatal stroke: clinical and neurophysiological associations. Dev. Med. Child Neurol. https://doi.org/10.1111/dmcn.14273

Wu, S., Mead, G., Macleod, M., Chalder, T., 2015. Model of Understanding Fatigue After Stroke. Stroke 46, 893-898. https://doi.org/10.1161/STROKEAHA.114.006647

Wu, Y.W., March, W.M., Croen, L.A., Grether, J.K., Escobar, G.J., Newman, T.B., 2004. Perinatal stroke in children with motor impairment: A population-based study 114, 612619.

Zewdie, E., Damji, O., Ciechanski, P., Seeger, T., Kirton, A., 2017. Contralesional Corticomotor Neurophysiology in Hemiparetic Children With Perinatal Stroke. Neurorehabil. Neural Repair 31, 261-271. https://doi.org/10.1177/1545968316680485 